ASSOCIAÇÃO INDÍGEN TEMBÉ DE SANTA MARIA DO PA (AITESAMPA): UM REL SOBRE A LUTA I DIREITOS ÉTNIC 


\section{ASSOCIAÇÃO INDÍGENA TEMBÉ DE SANTA MARIA DO PARÁ (AITESAMPA): UM RELATO SOBRE A LUTA POR DIREITOS ÉTNICOS}

\section{E D IMAR A N T ON IO FER N A N D S}

\section{A L M I R VITA L DA S I L VA}

UNIVERSIDAdE FEDERAL do PARÁ, BRASIL

\section{J A N E F E L I P E B E L T R Ã O}




\title{
ASSOCIAÇÃO INDÍGENA TEMBÉ DE SANTA MARIA DO PARÁ (AITESAMPA): UM RELATO SOBRE A LUTA POR DIREITOS ÉTNICOS
}

\section{Resumo}

Lutar pela observância da Constituição Federal de 1988 se constitui em esforço de grande envergadura, especialmente para as associações indígenas, instrumentos de luta na defesa e promoção dos direitos étnicos. As associações, formadas à semelhança das organizações não-indígenas, procuram desenvolver projetos que compreendam a afirmação de identidades étnicas das comunidades e representam os indígenas em negociações internas e externas, contribuindo para a construção da autonomia e autodeterminação dos povos indígenas. Exemplo disso é a Associação Indígena Tembé de Santa Maria do Pará (AITESAMPA), que representa os Tembé, conhecidos como de Santa Maria por terem sua Terra nos limites do município do estado do Pará. A Associação luta pelo reconhecimento identitário e pela demarcação de terras para seu sustento, visto que desde o século XIX, foram escorraçados de suas terras e obrigados a deslocamentos não desejados, até se estabelecerem no, hoje, município de Santa Maria. O estudo se debruça sobre a atuação da referida Associação, a partir da relevância dos "projetos" sociais e étnicos que permitem o fortalecimento da identidade dos Tembé. Analisam-se as estratégias elaboradas através de iniciativas denominadas "projetos", desenvolvidos pela Associação para a defesa dos direitos indígenas e promoção de diálogo com o Estado brasileiro e a sociedade não-indígena que teimam em não aceitá-los, especialmente porque são "desconhecidos" na literatura etnológica que trabalha mais a partir dos Tembé localizados no Alto Rio Guamá. O trabalho é desenvolvido a partir das narrativas indígenas e do acompanhamento da movimentação social. Nessa condução, os autores envolvidos possuem uma visão "implicada", pois dois são membros de povos indígenas e a não-indígena foi chamada a assessorá-los.

Palavras-chave: Direitos indígenas, identidade étnica, organizações indígenas, movimento indígena.

\section{THE INDIGENOUS ASSOCIATION OF TEMBÉ PEOPLE FROM SANTA MARIA DO PARÁ (AITESAMPA): A REPORT ON THE STRUGGLE FOR ETHNIC RIGHTS}

\begin{abstract}
To protect the Federal Constitution with regard to the rights of indigenous peoples is a task of a great level of difficulty. Non-governmental organizations such as the associations created to develop projects in promotion of ethnic rights and the understanding of ethnic identity represent indigenous
\end{abstract}


peoples interests in both internal and external negotiations as means to build autonomy and self determination. An example of such political action is the Indigenous Association of Tembé People from Santa Maria do Pará (AITESAMPA) as they have their land located within Pará State territory. AITESAMPA fights for the identity rights and survival needs of the Tembé people who were expelled from their original land in the Nineteenth Century and forced to walk about until finally relocated in Santa Maria municipality in Pará State territory. This study is dedicated to analyze the action of the Association from the perspective of social and ethnic initiatives which allow for the consolidation of the Tembe identity. It also analyzes strategies and topics originated in projects conceived with the purpose to protect Indigenous rights. The Association aims at establishing dialogue with Brazilian State and non-indigenous society who deny their rights and do not accept them. This Tembé group is not recognized within the ethnological literature which is mostly dedicated to the Tembé who are located at the Upper Guamá River. The investigation is developed from indigenous narratives and by following social movement. Authors are involved and have an implicated view as two are members of the Indigenous group and non-indigenous member has been summoned to aid them in their endeavour.

Keywords: Indigenous rights, ethnic identity, indigenous organization, indigenous movement.

\section{Asociación Indígena Tembé de Santa Maria del Pará (AITESAMPA): un relato sobre la lucha por los derechos étnicos}

\section{Resumen}

Luchar por la observancia de la "Constitución Federal de 1988" constituye un esfuerzo de gran proporción, especialmente para las asociaciones indígenas, instrumento de lucha en la defensa y promoción de los derechos étnicos. Las asociaciones, formadas a semejanza de las organizaciones no indígenas buscan desarrollar proyectos que comprendan la afirmación de identidades étnicas de las comunidades y representen a los indígenas en negociaciones internas y externas, contribuyendo a la construcción de la autonomía y autodeterminación de los pueblos indígenas. Ejemplo de esto es la Asociación Indígena Tembé de Santa Maria del Pará (AITESAMPA), que representa a los Tembé, conocidos como de Santa Maria por tener sus Tierras en los límites del municipio del estado del Pará. La Asociación lucha por reconocimiento identitario y por la demarcación de tierras para su supervivencia, una vez que desde el siglo XIX, fueron expulsados de sus tierras y obligados a desarticulaciones no deseadas, hasta se establecieren en el, hoy, municipio de Santa Maria. El estudio analiza sobre la actuación de la referida Asociación, a partir de la relevancia de los "proyectos" sociales y étnicos que permiten el fortalecimiento de la identidad de los Tembé. Se analizan las estrate- 
gias elaboradas tras iniciativas denominadas "proyectos", desarrolladas por la Asociación para la defensa de los derechos indígenas y promoción del diálogo con el Estado Brasileño y la sociedad no indígena que insiste en inaceptarlos, especialmente porque son "desconocidos" en la literatura etnológica que trabaja más a partir de los Tembé ubicados en el Alto Rio Guamá. El trabajo es desarrollado a partir de las narrativas indígenas y del acompañamiento del cambio social. En ese orden de ideas, los autores son involucrados, tienen una visión "comprometida", pues dos de ellos son miembros de pueblos indígenas y fue la no indígena la llamada a asesorarlos.

Palabras-clave: Derechos indígenas, identidad étnica, organizaciones indígenas, movimiento indígena. 


\section{AS ANDORINHAS, A AITESAMPA E A CORDA DE TRÊS "NÓS"}

A busca do povo Tembế por novos mecanismos de reestruturação e, também, por meios que pudessem oferecer maior autonomia e visibilidade frente às diferentes realidades do mundo globalizado, fez com que a comunidade se apropriasse de diversos sistemas essenciais à garantia da igualdade de direitos. A criação da AITESAMPA, em 2003, significou a possibilidade de representação jurídica frente à sociedade nãoindígena, além da atuação na elaboração de estratégias para conquista, defesa dos direitos e interesses da comunidade. Para além da criação, narra Silva:

"foi a gente que resolveu criar a Associação, e a partir daí na primeira assembléia, que houve nós tivemos a oportunidade de gritar aquilo que vinha nos sufocando a muito tempo... Aquele nó na garganta [se desfez] e podemos dizer que somos indígenas, que somos cidadãos de direito ... E que sempre estivemos vivos, nunca estivemos mortos."

Não poder dizer que se é quem é, significa ficar sufocado. Associados os Tembé se crêem cidadãos de direito! Portanto, para fins desta comunicação, entendese a Associação como instrumento fundamental do projeto de autodeterminação do povo Tembé e estruturada a partir de "indígenas em movimento", como indica Luciano (2006). É via tradição (re)apreendida "na mudança" consorciada às novas demandas sociais do grupo, que se busca "construir" estratégias para superar a redução terri- torial imposta pela colonização e o etnocídio/genocídio perpetrado anos a fio.

A história do nosso povo aqui, no município de Santa Maria do Pará, devese ao fato de que o território era área tradicional, ocupado por nossos ancestrais; nós existimos aqui há mais de um século, os registros são anteriores ao século XIX. Então se Santa Maria tem 48 anos de emancipação, antes integrava o município de Igarapé-Açú, pois era uma vila; antes de existir essa vila aqui, o nosso povo já existia/estava aqui dentro.

Portanto, é admissível falar de etnocídio, entendido como processo político imposto a uma etnia que compreende a "desintegração" cultural e linguística que não necessariamente implica em destruição física, mas que se desenvolve em contextos de extrema violência ou de "cordialidade" violenta. ${ }^{3} \mathrm{O}$ processo de etnocídio pode assumir contornos mais graves, os quais podem se configurar em genocídio, tomado como ódio racial e étnico cometido contra grupos específicos, configurando-se como ação que corrói as relações interétnicas e conduz ao extermínio físico. Entre as formas mais violentas de genocídio estão os casos de estupros (Benbassa 2010; Vito; Gill \& Short 2009).

A existência de etnocídio e a tentativa de genocídio são objeto de investigação que se realiza para escrever a história dos Tembé, como requereu a Associação, em fevereiro de 2010, quando realizaram seminário denominado Territorialidade Tembé. Desde então, os autores trabalham em conjunto e o presente trabalho é a primeira tentativa de escrever comunicação na qual indígenas/acadêmicos (Silva e Fernandes), 
militantes do movimento indígena (Silva e Fernandes) e antropóloga (Beltrão) se apóiam para trazer a público o caso dos Tembé "de Santa Maria".

O esforço de escrever a seis mãos (quatro indígenas e duas não-indígenas) exige perícia e prática que não se têm, portanto quando se afirma peremptoriamente algo, o dito por escrito é fruto de discussão que incorpora, necessariamente, o ponto de vista Tembé, no caso a extensa narrativa oral de Silva, pois ele é protagonista no cenário de adversidades. Evidentemente, a fórmula não muito frequente no meio acadêmico ainda carece aperfeiçoamento e nos causa algum desconforto, pois a pratica da interculturalidade é nova, pouco usual e difícil de ser expressa. ${ }^{4}$

Silva intervém, sempre que necessário, fazendo uso da palavra e ensinando, por exemplo, o que é a Associação e como funciona o dia-a-dia da movimentação política que une os indígenas:

"quem decide é a comunidade! Estou aqui só para coordenar reunião, e até quando a gente faz as reuniões, quem decide é a comunidade! A gente coloca as propostas e tudo [ questões a resolver] então quem decide é a comunidade, se ela achar que sim, bem, se não a gente vê. Por maioria então quem decide é a comunidade. E, assim começamos a trabalhar na união do nosso povo, o objetivo principal da nossa organização da nossa associação, é a união do nosso povo, pois uma andorinha só não faz verão, uma corda de três nós é mais difícil de se romper!"

\section{OS TEMBÉ E A "REVOADA" ÉTNICA}

Da família linguística Tupi-Guarani, do Tronco Tupi, os Tembé "de Santa Maria do Pará" são pouco conhecidos na literatura indigenista nacional, pois integram o grupo que viveu, muitos anos, acossado pelo mundo não-indígena e "oculto" pela impossibilidade de apresentar-se como indígena.

Os Tembé com os quais se trabalha são pessoas que, exceto os mais velhos, nasceram no Area $\bar{P}$ ou no Jeju ${ }^{6}$ aldeias cercadas pela "cidade que chegou até nós", como informa Alan, tesoureiro da Associação. Vivem na aldeia e dificilmente saem da aldeia, referindo quase que invariavelmente: "então minha vida toda foi aqui."

Viviam em meio aos não-indígenas, aparentemente sem problemas, até decidirem se assumir indígenas, em que pesem todos os problemas advindos da decisão. O fato é recente (antes as condições políticas não permitiam) e como relata Silva, rememorando os primeiros voos:

"só passamos a ter conhecimento sobre nossos direito, há mais ou menos dez anos quando os parentes do Alto Rio Guamá, o Piná [liderança Tembe] junto com o pessoal do CIMI [Conselho Indigenista Missionário] fizeram esse primeiro contato. Eles souberam que aqui tinha indígena, então eles vieram fazer esse primeiro contato."

Após a assumir a pertença étnica e criar a Associação é por intermédio da AITEMSAMPA que se encaminham os pleitos da comunidade pela efetivi- 
dade de direitos fundamentais. A associação é a "ferramenta" disponível para propugnar a valorização e (re) elaboração cultural proporcionando o desenvolvimento da comunidade de acordo com as especificidades, as aspirações e as necessidades, tal como são asseguradas constitucionalmente.

Não há como discutir a AITESAMPA sem pensar na responsabilidade sociopolítica em relação à comunidade, especialmente ao tratar de questões referentes: ao território, a gestão de recursos financeiros e nas intermediações das relações intra-étnicas "dentro e entre" as comunidade do Areal e do Jeju entre os Tembé de Santa Maria e os demais Tembé ${ }^{7}$ entre os Tembé de qualquer uma das coletividades e com os não-indígenas; e, especialmente, entre os Tembé com as autoridades junto as quais se reivindica algo.

As relações indicadas geram preocupações às lideranças Tembé, pois gerir organização que foge dos moldes conhecidos pela comunidade é o desafio maior, obrigando as lideranças indígenas a demandar conhecimentos técnicos, administrativos e jurídicos que possibilitem o entendimento do funcionamento burocrático da organização. Compreender o funcionamento de associação instituída pelos padrões não-indígenas é requisito básico para se manter de acordo com as regras e legislação vigente, uma vez que a não observância das normas pode acarretar a inadimplência da mesma e os problemas decorrentes do fato.

A Associação foi constituída em Assembléia, envolvendo os membros da comunidade e é composta pela Diretoria, Conselho de Base e Conselho Fiscal. São integrantes do Conselho de Base as pessoas mais velhas da comunidade, que assessoram a Diretoria da Associação e aconselham os membros da comunidade. A Diretoria, por sua vez, é composta pelo coordenador, vice-coordenador, secretário, vice-secretário, tesoureiro e vice-tesoureiro, os quais atuam em conjunto, encaminhando as demandas da comunidade e mediando as relações. Por fim, o Conselho Fiscal é composto por três pessoas, responsáveis por fiscalizar as ações da diretoria, assim como a aplicação dos recursos e o andamento dos projetos.

Entre as principais atribuições da Associação destacam-se a representação jurídica dos interesses da comunidade frente à sociedade nacional. Sobre o assunto, Matos destaca que "na condição de mediadores das relações interétnicas, as organizações indígenas assumem posições privilegiadas nos diálogos interculturais estabelecidos entre os povos indígenas e agentes não indígenas.” (2007: 29).

Além da representação externa, a Diretoria gerencia os recursos destinados à manutenção da comunidade, aos serviços de saúde, à educação, à agricultura, ao transporte, à alimentação em dias de festa e outros eventos entre tantas outras atribuições.

Estabelecida a Associação, agora cabe às lideranças o fortalecimento de políticas de reestruturação tanto física quanto cultural da comunidade, fortalecendo a identidade coletiva para fazer frente aos poderes constituídos. Desde a re- 
organização do povo e a criação da AITESAMPA, diversas foram as tentativas feitas junto à Fundação Nacional do Índio (FUNAI) solicitando a inclusão dos Tembé em seus cadastros e assistência de saúde e escolar. Entretanto, o órgão indigenista tem, constantemente, negado assistência, alegando que o povo não é reconhecido e que não tem como prestar atendimento sem antes fazer um estudo aprofundado do assunto. Como responder à "incompreensão" dos gestores públicos, pois "não temos culpa se a zona urbana veio a nós, queremos o que é nosso direito, porque somos indígenas e somos cidadãos de direitos", como sempre referem os Tembé.

\section{COMO DESATAR OS "NÓS"?}

As lideranças deixam claro, em conversas, que a FUNAI não se comporta como parceira; a morosidade e o tratamento dispensado aos Tembé é pouco respeitoso para dizer pouco. A forma de agir do órgão indigenista nega os direitos que a legislação assegura aos povos indígenas. A falta de apoio, que se traduz em não-assistência e em descaso, por parte do Estado, os fez buscar mecanismos que auxiliassem a luta e o reconhecimento do grupo como povo. Desde a criação da Associação, vários projetos foram pensados para suprir as diversas demandas da comunidade; projetos direcionados a luta pelo território, a melhorias na área de saúde, educação, economia, e propostas voltadas à execução de projetos ao fortalecimento da cultura, da língua e à afirmação da identidade étnica.
Os projetos tem sido uma das formas utilizadas para ter acesso aos recursos disponíveis; porém, assim como a gerencia da Associação, a implantação de projetos demanda um esforço significativo, pois as exigências a serem cumpridas são muitas e não estão de acordo com os modelos conhecidos pelo povo. O grande problema é que a maioria dos projetos não são pensados e elaborados pelos indígenas, ou seja, são pensados "de fora para dentro". $\mathrm{Na}$ comunidade, apenas um dos jovens concluiu o ensino superior (Pedagogia) e dois outros se encontram realizando graduação em Belém; dos dois, um é um dos autores deste texto, portanto ainda não há pessoas em número $\mathrm{e}$ com capacidade para gerenciar propostas “à moda dos brancos”.

Muitas entidades se propõem a apoiar projetos voltados aos povos indígenas, mas para ter acesso é preciso adequarse às normas dos editais, cumprindo os requisitos exigidos. A maioria dos projetos é elaborada por equipes de profissionais não-indígenas que aparecem como intermediadores, mas na realidade revelam-se algumas vezes "cavalos de tróia", pois parecem belos e majestosos, mas quando colocados em prática, revelam-se prejudiciais, fugindo dos padrões de vida do povo e prejudicando seu modo de vida e organização social.

No caso dos Tembé "de Santa Maria", vários tipos de projetos foram apropriados pela Associação desde a sua criação; alguns foram colocados em prática, outros foram apenas iniciados e outros ainda não saíram do papel. A seguir, 
analisam-se os documentos que Silva, na condição de presidente da entidade, se dispôs a trazer a público junto conosco. Incorporados ao texto, encontram-se os relatos de alguns dos interlocutores indígenas com o objetivo de demonstrar como os projetos podem ser benéficos ou não à luta dos Tembé.

No caso dos projetos que deram certo, a participação da comunidade em todas as etapas foi efetiva. O projeto de Formação para auto-demarcação do Território Indígena Jeju e Areal do povo Tembé de Santa Maria do Pará em parceria com o Fundo Brasil de Direitos Humanos pode ser citado com exemplo de projeto exitoso. Entre os objetivos do projeto destacam-se: (1) estratégias para retomada do território; (2) fortalecimento do vínculo com outras comunidades indígenas da região, especialmente com os demais Tembé; (3) capacitação das lideranças indígenas para reivindicar direitos e resgatar a cultura. ${ }^{8}$

O projeto foi elaborado pela comunidade em assembléias realizadas em 2007 e colocado em prática em 2008 e 2009; dentre os feitos, podemos destacar: (1) a visita a outras aldeias pelas lideranças indígenas com o objetivo de fortalecer os laços e falar sobre a luta do povo; (2) o levantamento da documentação que comprova a existência dos Tembé em Santa Maria; (3) as oficinas de autoidentificação e demarcação da terra indígena partilhando experiências de outros parentes; (4) a participação e apoio à participação dos membros da comunidade em eventos e mobilizações como o Grito dos Excluidos e Fórum Social Mundial.

A elaboração e a implantação do pro- jeto foram de extrema relevância no sentido de auxiliar o povo a estabelecer alianças com os demais povos indígenas da região, além de proporcionar às lideranças indígenas a elaboração de um relatório sobre a existência do povo Tembé e da luta por seus direitos. Portanto, uma primeira observação se faz pertinente: parcerias exigem participação e protagonismo, aí reside possibilidade de êxito. As informações do Fundo Brasil dão conta da importância da ação e a situação da terra, que assemelha-se a um nós sem possibilidade de "desatar", e deixa a todos incomodados.

\section{OS "NÓS" DO PROTAGONISMO}

No caso dos projetos que foram iniciados e não foram concluídos, cita-se o exemplo da Roça Consorciada, criado pela Prefeitura do Município e que se estruturava a partir do plantio de lavoura branca: milho, mandioca, feijão, o qual deveria ser de incumbência de grupos compostos por dez famílias.

O projeto não foi idealizado pela comunidade e nem mesmo discutido adequadamente. A implantação dependia da existência de terras para o plantio, o que não é a realidade vivida pelos "de Santa Maria”, não há terras de uso coletivo disponíveis. Assim, foram utilizadas terras de algumas famílias pertencentes aos grupos constituídos, fato que gerou pouca colaboração dos demais integrantes do grupo que auxiliavam na manutenção do roçado.

O problema maior era as famílias sem terra, que não se comprometiam com a manutenção da lavoura ou faziam de 
forma desigual entre elas, talvez por não se sentirem donos da lavoura que "acontecia" em pedaços de terra particular, além da distância das ditas terras para plantio, o que dificultava a manutenção. Considerando os impasses e as dificuldades, o fato é que nem todos se comprometeram, ficando o encargo para algumas famílias do grupo.

Como "era de se esperar", o projeto causou desentendimentos entre os membros dos grupos, prejudicando a vida social da comunidade. E Silva oferece o veredito: "quem sabe das nossas necessidades somos nós" e afirma que "para ter algum sucesso, os projetos precisam ser feitos com a necessária participação da comunidade, pois é ela que sabe das dificuldades." Portanto, projeto pensado "para a comunidade" e "não pela comunidade", pode até ser iniciado, mas fica inconcluso.

Continuando, apresenta-se projeto que não "saiu do papel", ficou nas ideias de alguns; é o projeto Casa de Mel. Uma vez mais a proposta veio da Prefeitura de Santa Maria do Pará e previa a implantação de uma Casa de Mel. Para tanto era necessária uma Associação constituída. Conhecedores da existência da AITESAMPA, os mentores do projeto convenceram o presidente da Associação de que seria um grande benefício para a comunidade; argumentaram que os Tembé perderiam o "benefício" se não aceitassem. Sem reunir a comunidade o presidente acabou aceitando o projeto e fornecendo os dados da Associação para receber os recursos.

Posteriormente, o presidente apresentou o projeto aos membros da comu- nidade e Diretoria da Associação que, em conjunto, analisou a proposta e concluiu que não era viável, pois muito abrangente; não atenderia somente a comunidade indígena e sim a vários grupos de produtores de mel do município, não oferecendo os benefícios que se supôs de início. Pelo contrário, iria trazer outros problemas pela interferência de não-indígenas na gerência da Casa de Mel. Solicitaram, então, o cancelamento do projeto e, como o dinheiro para a construção da casa estava na conta da Associação, devolveram sob críticas das pessoas responsáveis pelo projeto.

\section{TERRA É BASE DE TUDO}

Por intermédio da Associação, a comunidade tentou diversas vezes obter o reconhecimento étnico e o atendimento merecido, porém, como mencionado anteriormente, a FUNAI sempre agiu no sentido de negar direitos. A relação começou a mudar em uma reunião realizada no Ministério Público Federal (MPF) com o presidente da FUNAI, Márcio Augusto Freitas Meira, recentemente, dia 8 de abril de 2011. Durante a reunião foi redigido um documento de reconhecimento da pertença étnica Tembé, elaborado e assinado pelas lideranças indígenas que representavam, na ocasião, as comunidades do Alto Rio Guamá, do Gurupi e de Tomé-Açu. O documento é vitória da tenacidade dos "de Santa Maria", pois foram reconhecidos pelos parentes na região e assim ganham respaldo à luta garantindo a continuidade enquanto povo.

Mas os problemas não cessaram. Avali- 
ando o processo Silva diz:

"mandamos vários ofícios à $\mathrm{FU}$ NAI, tivemos audiência, fomos ao MPF, fizemos as articulações. Está prevista para agosto a vinda de uma antropóloga para fazer um estudo mais aprofundado sobre a nossa área. Até agora, o que tivemos aqui foram duas antropólogas, primeiro foi a Geovana, que fez o cadastramento das famílias, passou três ou quatro dias. Daí veio outra a Marlinda que passou um dia e meio e nada! Até hoje não saiu coisa alguma, nós não temos conhecimento do estudo antropológico que elas fizeram, porque para nós, não é um estudo antropológico. Consideramos, apenas, como uma visita, porque no nosso conhecimento um estudo antropológico, ele tem que durar mais ou menos 40 a 50 dias para pessoa saber realmente o que é ou o que deixa de ser."

Faz uma pausa e usando da comparação, informa reflexivo:

"por exemplo eu te olho aqui, eu posso te ver rapidamente,posso ter uma visão rápida, mas para eu chegar a conclusão de quem és ou deixas de ser, sou obrigado a conviver pelo menos um mês e conversar. Então é isso o que elas viram fazer aqui foi somente uma visita, não fizeram a vistoria completa $\mathrm{da}$ área, não visitaram o cemitério, e foi por esse motivo, também, que a FUNAI ... eles tem falado, acham não há indígenas aqui."

Para contestar o trabalho que ficou por fazer e demonstrando a determinação em requerer direitos, diz Silva:

"nós resolvemos fazer um projeto pelo Fundo Brasil de Direito Humanos e escolhemos duas pessoas da comunidade o Alan e a Raimunda, pra fazer essa pesquisa e produzir o relatório sobre a historia do nosso povo aqui, no que é hoje o município de Santa Maria do Pará."

$\mathrm{Na}$ área da saúde, a Associação encaminhou diversas reivindicações de atendimento junto à Fundação Nacional da Saúde (FUNASA) solicitando os serviços; entretanto jamais foram contemplados porque não eram cadastrados e atendidos pela FUNAI. Com a constante omissão, os indígenas de Santa Maria fizeram uma aliança com os indígenas do Alto Rio Guamá e criaram alternativa provisória ao problema; no segundo semestre de 2011 a assistência à saúde será feita a partir do polo que atende os indígenas do Alto Rio Guamá. Há promessa, ainda não cumprida, de que a partir de 2011 os recursos permitirão a criação de um polo de assistência em Santa Maria do Pará.

A Associação, em parceria com as lideranças, também é responsável por denunciar a poluição dos rios, o uso indiscriminado de agrotóxicos pelos fazendeiros às proximidades das aldeias, o uso de bombas em pesca predatória feitas por pescadores regionais. Tais ocorrências têm gerado muitas preocupações aos Tembé com relação à preservação do território e uso sustentável do mesmo, pois a luta para reconquistá-lo foi intensa. Quando se tratam de terras tradicionalmente ocupadas pelos indígenas, o caput do artigo 231 da Constituição Federal define claramente que cabe à União demar- 
car, proteger e fazer respeitar todos os bens ali existentes.

É Carvalho (2006) que define por comparação a importância de conceber as terras indígenas como domicílio por direito, respaldada pelo artigo $5^{\circ}$, inciso XI da Constituição Federal de 1988, que veda a entrada de qualquer pessoa sem o consentimento do morador, salvo em algumas exceções.

"Nessa concepção, as terras indígenas são o domicílio por direito, a habitação necessária à sobrevivência física e cultural dos povos indígenas. Concilia-se perfeitamente com a intenção do princípio da casa como asilo inviolável, haja visto que o legislador buscou estabelecer o território como espaço para a proteção dos índios.” (2006: 93)

Nossa compreensão indica que os Tembé assumiram a responsabilidade pela proteção do território, procurando denunciar as irregularidades em eventos e na mídia, chamando atenção do Estado que teima em ser moroso, deixando claro o descaso e a falta de vontade política dos agentes públicos.

\section{CONCLUINDO "COM DÚVIDAS"}

O caminho dos Tembé é longo, exige muita articulação para o pleno reconhecimento da identidade diferenciada, controle da autonomia e protagonismo, razão que torna a Associação fundamental ao projeto de autodeterminação, buscando conciliar a tradição e as novas demandas sociais do grupo face à redução territorial, aos agravos produzidos pelos inúmeros empreendi- mentos no território. Admite-se, então, como quer Luciano (2006), a organização indígena como forma por intermédio da qual uma comunidade ou povo indígena organiza seus trabalhos e sua luta pela vida coletiva e não simplesmente como uma instituição jurídicoadministrativa. E, como reflete Silva, sem Associação é impossível à comunidade caminhar, tudo se tornaria mais difícil, não funcionaria. Ficaria cada qual por si e salve-se quem puder!

Os direitos conquistados a partir da Associação precisam ser mantidos, mas avançar é fundamental para que a efetividade torne-se realidade. O desafio é o acesso à terra, educação e saúde para reinventar o cotidiano em meio aos não-indígenas. $\mathrm{O}$ trabalho apenas iniciou.

\section{AGRADECIMENTO}

Texto apresentado e discutido no GT 06 Antropologia, Direitos Coletivos, Sociais e Culturais, por ocasião do II ENADIR - Encontro de Antropologia do Direito, realizado no período compreendido entre 31.08 e 02.09.2011, nas dependências do Conjunto Didático de Filosofia e Ciências Sociais da Faculdade de Filosofia, Letras e Ciências Humanas (FFLCH) da Universidade de São Paulo (USP), campus da capital, promovido pelo Núcleo de Antropologia do Direito (NADIR). Agradecemos as contribuições recebidas na oportunidade.

\section{NOTAS}

${ }^{1} \mathrm{O}$ nome "Tembê", ou sua variante Timbé, constitui um nome que provavelmente lhes foi atribuído pelos regionais. De acordo com o linguista Max Boudin, timbeb significaria "nariz chato". Dentre os 
assim chamados, os Tembé constituem o ramo ocidental dos Tenetehara. O grupo oriental é conhecido por Guajajara. Sua autodenominação é Tenetehara, que significa gente, índios em geral ou, mais especificamente, Tembé e Guajajara. Fonte: http://pib.socioambiental.org/pt/povo/ tembe/1021. Acesso dia 07.06.2010.

2 A longa narrativa de Silva é integrada ao texto por conta da co-autoria. Trata-se de um "texto" oral, ao gosto da tradição indígena, a qual ao ser escrita padece de todos os problemas de tradução da oralidade. Os realces são necessários para fazer jus à autoria, talvez o caminho ainda esteja torto, mas aos poucos vamos atravessando varadouros e estabelecendo novas formas do "escrever acadêmico", pois o tempo é agora, a História "desde abaixo" se faz tropeçando, mas é hora de abrigar relações simétricas entre saberes.

3 Cordialidade que pode ser "lida" nas ações do Estado para educar o povo para o trabalho aliada à ação das missões religiosas em cristianizar. Os meandros do processo estão sendo estudados por Fernandes, a partir da documentação recolhida pelos Tembé com apoio do Fundo Brasil de Direitos Humanos. Os estudos integram a proposta de dissertação de mestrado de Fernandes denominada: Luta por direitos: estudo sobre a Associação Indígena Tembé de Santa Maria do Pará (AITESAMPA), em andamento, sob a orientação de Beltrão. O Núcleo Indígena de Santo Antônio do Prata depois conhecida como Colônia Santo Antônio do Prata on Colônia do Prata que além do indígenas da região, era Instituição Asilar que abrigava hansenianos é estudada por Fernandes e Beltrão por solicitação dos Tembé e com apoio de Silva. Sobre o assunto consultar: Rizzini, Irmã. A união da Educação com a Religião nos Institutos Indígenas do Pará (1883-1913). Universidade do Estado do Rio de Janeiro; Disponível em http://www.faced.ufu.br/colubhe06/anais/ arquivos/484IrmaRizzini.pdf e Muniz (1913).

4 Compreendida como complementação entre saberes, forma de reorientação solidária da relação entre conhecimentos distintos procurando adotar práticas que promovam novas formas de convivência interativa e ativa de saberes (no caso, tradicional e científico) que pode garantir diálogo simétrico. Valorizando ambos os conhecimentos. Para compreender as novas perspectivas interculturais, e a importância da mesma, conferir: Santos (2004).

5 A aldeia Areal ou "Aldeia do Miguel" como também é conhecida está localizada a, aproximadamente, sete quilômetros do centro da cidade de Santa Maria, à direita da vicinal conhecida como Travessa Linha do Telégrafo. Nem todos os integrantes da comunidade indígena do Areal moram no local, pois como o território não é demarcado, os membros distribuem-se em algumas vilas próximas à aldeia, são elas: São Francisco, Nossa Senhora do Bom Parto, São Silvério, Travessa do Espírito Santo, Travessa São Domingos e Nossa Senhora do Perpétuo Socorro. Nas vilas convivem com não-indígenas e sofrem preconceito por se identificarem como Tembé.

${ }^{6}$ A aldeia Jeju está localizada a cinco quilômetros da cidade de Santa Maria, à margem esquerda da BR-316 sentido oposto à aldeia Areal. Na aldeia Jeju a situação não é muito diferente, o processo de invasão das terras mudou completamente a rotina dos indígenas que ali vivem. Atualmente, as famílias moram dispersas em meio aos não-indígenas na vila do Jejú e nos arredores, porém reúnem-se para conversas sobre as demandas da comunidade, em assembléias da AITESAMPA ou mesmo em dias de "festa da cultura" como costumam chamar quando de reúnem para cantar e "pular" o kae kae. 
7 Há mais cinco territórios que pertencem aos parentes, no Pará, mas diferente da situação vivida pelos "de Santa Maria", os demais possuem terras registradas e homologadas, a saber: Alto Rio Guamá, Marakaxi, Tembé e Turé-Mariquita I e II.

${ }^{8}$ É interessante observar que ao se referir a resgate, os Tembé trabalhando as "perdas", não como perda em si, mas como possibilidade de mesmo sob intensa opressão são senhores da dinâmica cultural. A fala dos protagonistas é no sentido de produzir rearranjos sistêmicos de acordo com os interesses políticos. Assim são pensadas as aulas de língua materna, as oficinas de cânticos e danças, a educação escolar, entre outras demandas e providências.

\section{REFERÊNCIAS}

Benbassa, E. 2010. Ethnocide e Génicide. Verbetes, in Dictionnaire des racismes, de léxclusion et des descriminations. Rodese (Espagne), Larousse à presént, pp. 334 e 368-374.

Carvalho, J. B. 2006. Terras indígenas: a casa como asilo inviolável, in Povos Indígenas e a Lei dos "Brancos": o direito a diferença. Organizado por A. V. Araújo. pp. 85-101. Brasilia: Ministério da Educação, Secretaria de Educação Continuada, Alfabetização e Diversidade; LACED/Museu Nacional. Disponível, também, em: www.laced.mn.ufrj/trilhas.

Luciano, G. dos S. 2006. O indio brasileiro: o que você precisa saber sobre os povos indigenas no Brasil hoje. Vol. 1, Brasilia: MEC/SECAD, LACED/ Museu Nacional. Disponível, também, em http:/ /www. laced.mn.ufri.br/trilhas/.

Matos, M. H. O. 2007. Execução e gestão de projetos indígenas: criando tradição e/ou reflexão, in Povos indigenas: projetos e desenvolvimento. Organizado por C. N. I. de Souza; A. C. de Souza Lima; F. V. R. de Almeida e S. Wentzel. pp. 21-36. Rio de Janeiro: Contra Capa.
Muniz, P. 1913. O Instituto Santo Antonio do Prata (Municipio de Igarapé-Assú). Belém: Typ. da Livraria Escolar.

Rizzini, I. A união da Educação com a Religião nos Institutos Indígenas do Pará (18831913). Universidade do Estado do Rio de Janeiro. Disponível em http:// www.faced.ufu.br/colubhe06/anais / arquivos/484IrmaRizzini.pdf .

Santos, B. de S. 2004. A universidade no século XXI: para uma reforma democrática e emancipatória da universidade. São Paulo: Cortez.

Vito, D. de; A. Gill e D. Short. 2009. A tipificação do estupro como genocídio. SUR Revista Internacional de Direitos Humanos. Ano 6(10): 29-51. Disponível, também, em: http://www. surjournal.org/eng/index.php.

Documento

Doc. 3, No. 19, Arquivo - Vice Provincial Capuchinha do MA-PA.

Sites

http://pib.socioambiental.org/pt/c/nobrasil-atual/quantos-sao/introducao.

http://pib.socioambiental.org/pt/povo/ tembe/1021

http://www.trilhasdeconhecimentos.etc. $\mathrm{br} /$ livros/index.htm

http://earth.google.com/intl/pt/

Recebido em 24/07/2011.

Aprovado em 12/09/2011. 